\title{
PERBANDINGAN PROBLEM BASED LEARNING (PBL) DENGAN KOOPERATIF TIPE TGT (TEAM GAME TOURNAMENT) MENGGUNAKAN MEDIA PERMAINAN SOS TERHADAP HASIL BELAJAR SISWA PADA MATERI ASAM BASA
}

\section{Comparison Of Problem Based Learning (PBL) With TGT Type Cooperative (Team Game Tournament) Using Sos Game Media To Student Learning Outcomes On Asam Basa Materials}

\author{
Saribatul Aslamiah, Antoni Pardede, Raden Roro Ariessanty Alicia Kusuma \\ Wardhani \\ Program Studi Pendidikan Kimia Fakultas Keguruan dan Ilmu Pendidikan \\ Universitas Islam Kalimantan (Uniska) Muhammad Arsyad Al Banjari, Banjarmasin \\ *email: saribatu198@gmail.com
}

\begin{abstract}
Abstrak. Penelitian ini bertujuan untuk mengetahui perbandingan dan hasil belajar siswa dengan menerapkan metode TGT menggunakan media permainan SOS (kelas eksperiment) dengan model pembelajaran problem based learning sederhana (kelas kontrol). Peneitian ini menggunakan penelitian eksperiment semu desain penelitian nonekuivalen control group design, mengambil 2 kelas sebagai sampel eksperimen dan kontrol dengan masing-masing siswa 33 orang Berdasarkan hasil analisis data penelitian yang didapat, pada siswa kelas XI ipa 2 (kelas eksperiment) mendapatkan hasil belajar kognitif siswa rata-rata nilai 81,21, kemudian dibandingkan hasil belajar kognitif siswa kelas XI ipa 1 (kelas kontrol) yang memiliki rata-rata nilai 72,27. Berdasarkan hal tersebut dapat disimpulkan penggunaan model pembelajaran TGT dengan media permainan SOS efektif dan berpengaruh positif terhadap hasil belajar siswa dalam ranah kognitif
\end{abstract}

Kata kunci : TGT, Model pembelajaran

\begin{abstract}
This research aimed to determine the comparison of student learning outcomes by applying the TGT method using the SOS game media (experimental class) and the ones with simple problem based learning model (control class). This research used quasi-experimental research, nonequivalent control group design, chose 2 classes as experimental and control samples with 33 students each. Based on the data analysis result, students of XI IPA 2 (experimental class) gained an average score of 81.21, it was then compared to the cognitive learning outcomes of students in class XI IPA 1 (control class) which had an average score of 72.27. Therefore, it can be concluded that the use of the TGT learning model with SOS game media was
\end{abstract}


effective and had a positive effect on student learning outcomes in the cognitive domain.

Keywords: TGT, learning model

\section{PENDAHULUAN}

Model pembelajaran merupakan salah satu hal yang sangat penting dalam proses belajar mengajar agar tercapainya hasil belajar yang optimal. Salah satu model pembelajaran yang dapat menarik minat siswa adalah model pembelajaran kooperatif tipe TGT (Team Game Tournament). TGT merupakan model pembelajaran yang digunakan untuk meningkatkan aktivitas dan hasil belajar siswa, dimana siswa bermain dengan anggota tim lain untuk memperoleh poin bagi timnya masing-masing. Permainan ini disusun oleh guru dalam bentuk kuis berupa pertanyaan yang berkaitan dengan materi pelajaran, sehingga siswa aktif dan hasil belajar pun meningkat (Kurniawati, 2019).

Problem Based Learning (PBL) adalah suatu model pembelajaran yang didasarkan pada prinsip menggunakan masalah sebagai titik awal akuisisi dan integrasi pengetahuan baru. PBL adalah salah satu model pembelajaran yang berpusat pada peserta didik dengan cara menghadapkan para peserta didik tersebut dengan berbagai masalah yang dihadapi dalam kehidupannya. Dengan pembelajaran model ini, peserta didik dari sejak awal sudah dihadapkan kepada berbagai masalah kehidupan yang mungkin akan ditemuinya kelak pada saat mereka sudah lulus dari bangku sekolah (Saleh, 2013). Media juga digunakan dalam pembelajaran yang dapat memicu pikiran, perasaan, perhatian dan kemauan siswa untuk belajar. Media permainan SOS yang digunakan dalam penelitian ini adalah media permianan yang berjenis sama dengan media permainan monopoli dan ular tangga

Di sekolah menengah atas (SMA) Negeri 12 Banjarmasin ada beberapa kendala dalam proses pembelajaran, diantaranya; jadwal mata pelajaran kimia kelas XI pada pukul 13.30 - 16.00 wita yang menyebabkan kurang efektifnya proses belajar mengajar sehingga siswa kurang fokus dalam belajar dan memperhatikan guru mengajar. Media yang digunakan guru saat mengajar sangat terbatas seperti papan tulis. Selain hal tersebut materi asam basa diajarkan pada awal semester genap, siswa masih dalam suasana libur, sehingga siswa perlu penyesuaian dan beradaptasi kembali. Masa transisi ini menyebabkan kurang optimalnya hasil belajar siswa dan pencapaian KKM pada materi asam basa masih rendah. Nilai rata-rata bebarapa siswa pada mata pelajaran asam basa paling rendahnya berkisar 40,0 dan yang paling tinggi 90,0, namun untuk nilai ratarata pencapaian KKM siswa berkisar $60-70$.

Berdasarkan permasalahan tersebut diatas perlu dilakukan penelitian, yaitu penerapan model pembelajaran yang dapat membuat siswa senang, tidak bosan dan memotivasi belajar materi asam basa secara aktif, kreatif dan interaktif, dengan tujuan apakah dengan menerapkan model yang berbeda tujuan tersebut dapat tercapai, kemudian membandingkannya dengan model pembelajaran yang sering digunakan agar dapat mengetahui hasilnya. Salah satu upaya agar dapat memecahkan masalah tersebut adalah dengan menerapkan model pembelajaran Kooperatif tipe TGT dengan bantuan permainan SOS. Kooperatif dengan bantuan media permainan SOS diharapkan dapat 
membantu siswa untuk belajar materi asam basa dengan aktif, kreatif dan menyenangkan serta memotivasi siswa dan meningkatkan hasil belajar

\section{METODE PENELITIAN}

Penelitian ini menggunakan penelitian eksperiment semu, yang dimana kondisi dimanipulasi oleh peneliti sesuai dengan kebutuhan peneliti. Dalam kondisi yang telah dimanipulasi , biasanya dibuat kelompok kontrol dan kelompok eksperimen. Kepada kelompok eksperimen diberi perlakuan atau stimulus tertentu sesuai dengan tujuan penelitian. Penelitian menggunakan teknik data kuantitatif, dimana kegiatan penelitian berupa pengolahan data berupa statistik, data hasil dan hasil survei, dengan tujuan untuk mendukung pemahaman, menguji hipotesis/teori dan memverifikasinya.

Desain penelitian nonekuivalen control group design desain ini hampir mirip dengan pretest-posttes control grup design, hanya saja pada desan ini kelompok eksperimen dan kelompok kontrol tidak dipilih secara random (Sugiyono, 2016) dapat dilihat dari tabel 1.

Tabel 1. Desain penelitian nonekuivalen control group design

\begin{tabular}{ccc}
\hline Kelompok/kelas & Perlakuan & Post-test \\
\hline XI IPA 1 (Eksperimen) & $\mathrm{X}$ & $\mathrm{Y}_{1}$ \\
& - & $\mathrm{Y}_{1}$ \\
\hline
\end{tabular}

Dengan mengambil dua kelas, yaitu XI IPA 1 sebagai kelas eksperimen dan XI IPA 2 sebagai kelas kontrol. Setiap kelas mendapat materi dan tes yang sama tetapi diberikan perlakuan yang berbeda dalam metode pembelajarannya. Kelas eksperimen diberi perlakuan dengan menerapkan model pembelajaran kooperatif tipe TGT menggunakan media permainan SOS, sedangkan kelas kontrol dalam proses belajarnya menggunakan sistem PBL sederhana

\section{HASIL DAN PEMBAHASAN}

Sebelum dilakukan uji hipotesis, terlebih dahulu dilakukan uji prasyarat yaitu normalitas dan homogenitas. Hasil uji normalitas dan homogenitas dapat dilihat pada gambar 1 dan gambar 2.

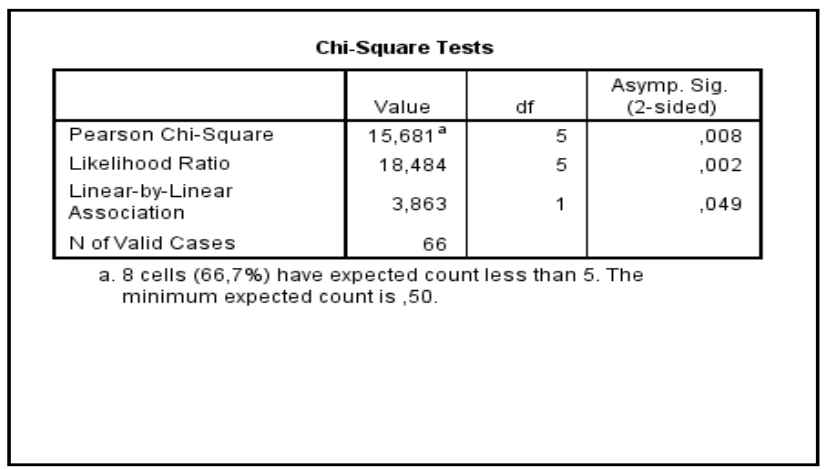

Gambar 1. Output hasil uji normalitas dengan chi-square test 
Berdasarkan data tabel hasil uji SPSS diatas, diketahui nilai Asymp.sig pada pearson Chi-Square adalah sebesar 0,008. Karena nilai Asymp.sig 0,008 $<0,05$, maka dapat disimpulkan bahwa hasil post-tes berdistribusi normal.

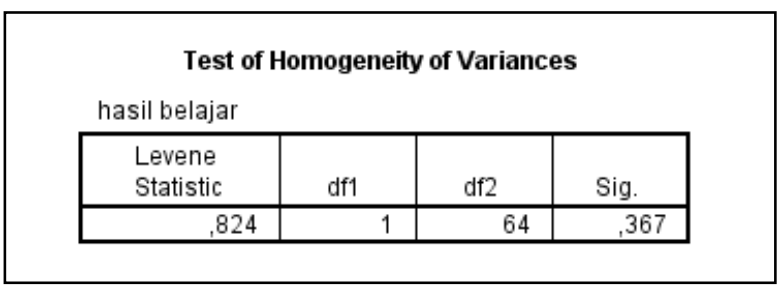

Gambar 2. Output hasil uji homogenitas

Berdasarkan tabel output hasil tes homogenitas menggunakan SPSS, diketahui nilai dari signifikansi (sig.) variabel hasil belajar siswa kelas kontrol dan eksperimen adalah sebesar 0,367. Karena nilai sig. 0,367>0,05 dapat disimpulkan bahwa varians data hasil belajar siswa kelas kontrol dan eksperimen adalah homogen. Setelah dilakukan uji prasyarat, kemudian dilakukan uji hipoesis menggunakan jalur paramterik denga uji t independent. Data hasil uji hipotesis menggunakan uji- $\mathrm{t}$ independent dapat dilihat pada gambar 3 di bawah ini.



Gambar 3. Output hasil uji hipotesis mengunakan uji-t independent

Berdasarkan gambar output diatas hasil uji-t data post-test siswa menggunakan SPSS diketahui nilai sig. 0,367 >0,05 maka dapat diartikan varians data amtara kelas kontrol dan eksperimen adalah sama atau homogen. Diketahui nilai pada bagian sig.(2-tailed) sebesar 0,049 $<0,05$ maka sebagaimana dasar pengambilan keputusan dalam uji independent sampel, dapat disimpulkan bahwa $\mathrm{H}_{0}$ ditolak dan $\mathrm{H}_{1}$ diterima.

Data penelitian diperoleh dengan melakukan perbandingan hasil evaluasi belajar (post-test). Berdasarkan data hasil penelitian, diperoleh data berupa nilai evaluasi hasil belajar siswa (post-test). Pada pertemuan terakhir pebelajaran siswa diberikan soal post-test sebanyak 10 butir soal pilihan ganda dengan 5 pilihan jawaban. Kemampuan akhir siswa setelah menggunakan model pembelajaran kooperatif tipe TGT (Team Game 
Dalton : Jurnal Pendidikan Kimia dan Ilmu Kimia, Volume 3 Nomor 2, November 2020

Tournament) menggunakan media pembelajaran permainan SOS dianalisis dari posttest. Data hasil belajar kelas eksperimen dan kontrol disajikan pada Gambar 4 dan 5.

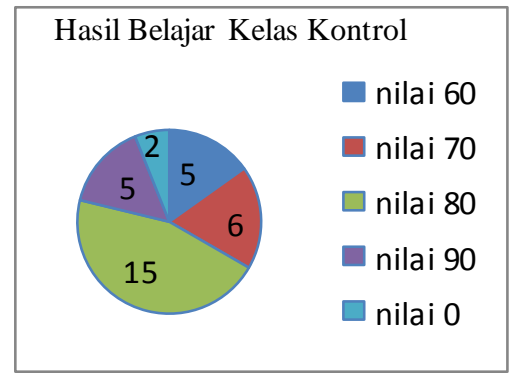

Gambar 4. Data hasil belajar kelas kontrol

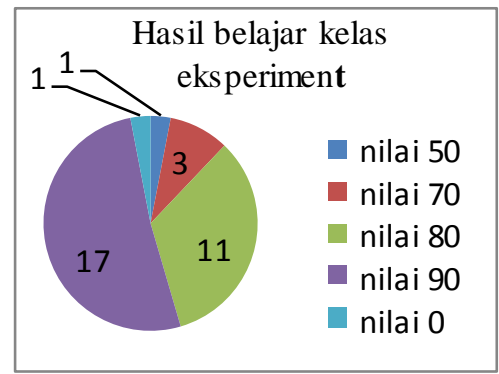

Gambar 5. Data hasil belajar kelas eksperimen

Berdasarkan Gambar 4 dari 33 responden yang diambil sebagai sampel dapat dilihat sebanyak 2 orang dengan nilai 0, 5 orang dengan nilai 60, 6 orang dengan nilai 70,15 orang dengan nilai 80 dan 5 orang dengan nilai 90. Berdasarkan Gambar 5 dari 33 responden yang diambil sebagai sampel dapat dilihat sebanyak 2 orang dengan nilai 0, 1 orang dengan nilai 50, 3 orang dengan nilai 70, 11 orang dengan nilai 80 dan 17 orang dengan nilai 90

Dari hasil keseluruhan nilai posttest siswa yang telah diperoleh, untuk mengetahui tingkat hasil belajar siswa kelas kontrol dan eksperimen apakah terdapat peningkatan, dilakukan perbandingan rata-rata nilai posttest siswa, hasilnya sebagai berikut :

Tabel 2. Rata-rata nilai siswa kelas kontrol dan eksperimen

\begin{tabular}{ccc}
\hline Nilai & $\begin{array}{c}\text { Post-test } \text { (kelas } \\
\text { Kontrol) }\end{array}$ & $\begin{array}{c}\text { Post-test } \text { (kelas } \\
\text { Eksperimen) }\end{array}$ \\
\hline $\begin{array}{c}\text { Rata-rata kelas } \\
\text { Selisih }\end{array}$ & 72,27 & 81,21 \\
\hline
\end{tabular}


Berdasarkan tabel 2 diatas diperoleh nilai rata-rata untuk kelas kontrol adalah 72,27 , sedangkan kelas eksperimen memiliki nilai rata-rata 81,21 dengan selisih 8,94\%. Berdasarkan tabel 10 dapat diketahui bahwa terjadi perbedaan nilai rata-rata yang signifikan antara kelas kontrol nilai rata-rata nilai dengan kelas eksperimen nilai ratarata. Angka tersebut menunjukan bahwa model pembelajaran yang diterapkan berpengaruh terhadap hasil belajar siswa, karena siswa menjadi lebih aktif ketika belajar sambil bermain.

Penerapan metode pembelajaran kooperatif tipe TGT (Team Game Tournament) menggunakan media permainan SOS ini melatih siswa untuk bekerjasama dalam kelompok diskusi dalam permainan sehingga terciptanya suasana kompetensi antara kelompok kecil. Menggunakan tim kerja dan turnamen yang berupa permainan akademik yang dimainkan oleh siswa dengan anggota tim lain untuk menyumbangkan poin bagi skor timnya tanpa harus ada perbedaan status (Cahyaningsih, 2017). Dalam metode ini proses belajar-mengajar siswa aktif dalam berdiskusi antar kelompok untuk menjawab kuis-kuis yang telah guru siapkan dalam permainan. Aktivitas belajar dengan permainan yang dirancang dalam pembelajaran kooperatif model TGT memungkinkan siswa dapat belajar lebih rileks disamping menumbuhkan tanggung jawab, kejujuran, kerja sama, persaingan sehat dan keterlibatan belajar. Dalam setiap pertandingan masing-masing kelompok diwakili oleh satu orang, sehingga dalam satu meja pertandingan terdiri dari wakil-wakil kelompok yang bertanding dengan kemampuan setara. Pada penerapan model pembelajaran PBL penggunaan model pembelajaran tersebut secara berulang-ulang sehingga membuat siswa kurang bersemangat dalam aktifitas belajarnya.

media pembelajaran yang digunakan juga dapat membantu guru untuk menciptakan suana belajar menjadi lebih hidup, tidak monoton dan tidak membosankan. Artinya guru dapat menciptakan berbagai situasi kelas, menentukan berbagai macam metode pengajaran dan menciptakan iklim emosional yang sehat diantara peserta didik dan meningkatkan daya minat belajar (Tafonao, 2018).

Nilai rata-rata peserta didik memiliki perbedaan dari aspek kognitif ini tidak terlepas dari adanya pengelolaan dimensi sosial peserta didik dalam model pembelajaran kooperatif tipe Teams Games Tournaments melalui teknik bermain ketika peserta didik mengerjakan soal turnamen maupun saat berdiskusi kelompok. Peserta didik dapat membangun struktur kognitif secara berkelompok. HASILKajian teoritis menunjukkan bahwa belajar secara kooperatif dapat memotivasi individu untuk berprestasi melalui belajar dan kerja secara berkelompok dibandingkan dengan belajar sendiri (Wahidah 2016).

Nilai rata-rata kelas eksperimen lebih tinggi diyakini dikarenakan adanya penerapan model pembelajaran TGT menggunakan media permainan SOS saat proses pembelajarannya. Siswa diberikan arahan belajar sambil bermain dan kemudian menjawab kuis-kuis yang berhubungan dengan materi bahan ajar guru sebagai pengulangan materi pembelajaran. Bermain sambil belajar juga dapat mengurangi kejenuhan siswa dalam proses pembelajaran dan turnamen kecil dalam permainan dapat membantu siswa bekerja sama dalam mempelajari materi dan memotifasi daya ingat siswa terhadapa materi yang diajar oleh guru. Hasil yang ditunjukkan tersebut sejalan dengan hasil penelitian yang dilakukan Mahmudah dkk (2019) bahwa model TGT memiliki pengaruh positif terhadap hasil belajar. 


\section{SIMPULAN}

Berdasarkan hasil analisis data penelitian yang didapat dari penerapan 2 model pebelajaran yang berbeda yaitu metode TGT menggunakan media permainan SOS dengan model pembelajaran problem based learning sederhana. Pada penggunaan model pembelajaran TGT (team games turnament) menggunakan media permainan SOS siswa kelas XI ipa 2 mendapatkan hasil belajar kognitif siswa rata-rata nilai 81,21, kemudian dibandingkan hasil belajar kognitif siswa kelas XI ipa 1 yang memiliki rata-rata nilai 72,27 dengan menerapkan model pembelajaran problem based learning sederhana. Berdasarkan hal tersebut dapat disimpulkan penggunaan model pembelajaran TGT dengan media permainan SOS efektif dan berpengaruh positif terhadap hasil belajar kognitif siswa.

\section{DAFTAR RUJUKAN}

cahyaningsih, U. (2017). Pengaruh Model Pembelajaran Kooperatif Tipe Team Games Tournament (TGT) Terhadap Hasil Belajar Matematika Siswa SD. Jurnal Cakrawala Pendas, 3(1), 1-5.

Kurniawati, D., Ainy, C., \& Hidayatullah, A. (2019). Pembelajaran Modelteams Games Tournament Dengan Media Engklut (Engklek Ular Tangga) Pada Pembelajaran Matematika. Matematics Paedagogic, 4(1), 57-65.

Mahmudah, S., Yuridka, F., Mashuri, M. T. (2019). Komparasi Pembelajaran Kimia Menggunakan Metode Teams-Games Tournament Dan Team-Assisted Individualization Terhadap Hasil Belajar Pada Materi Ajar Tata Nama Senyawa Kelas X SMA Negeri 12 Banjarmasin. Dalton : Jurnal Pendidikan Kimia dan Ilmu Kimia, 2(1), 16-21.

Saleh, M. (2013). Strategi Pembelajaran Fiqh Dengan Problem-Based Learning. Jurnal Ilmiah Didaktika, 4(1), 1-9.

Sugiyono. (2016). Metode Penelitian Kuantitatif, Kualitatif Dan R\&D. Bandung : PT Alfabet.

Tafonao, T. (2018). Peranan Media Pembelajaran Dalam Meningkatkanminat Belajar Mahasiswa. Jurnal Komunikasi Pendidikan, 2(2), 103-114.

Wahidah, L. (2016). Penerapan Model Pembelajaran Kooperatif Tipe Team Games Tournament (TGT) Untuk Meningkatkan Hasil Belajar IPS Siswa Kelas IV SD Negeri 06. Skripsi. Lampung : Fakultas Keguruan Dan Ilmu Pendidikan Universitas Lampung. 